\title{
Iron, Zinc, Manganese and Copper Intakes in Japanese Children Aged 3 to 5 Years
}

\author{
Miho Goshima $^{1}$, Taeko Murakami ${ }^{1}$, Haruo NAKAgaki ${ }^{1}$, Tomiko ShiBATA ${ }^{1}$, \\ Tomoko SugIYAMA ${ }^{1}$, Kazuo KATO ${ }^{1}$, Naoki NARITA ${ }^{1}$ and Mamoru NishIMUTA ${ }^{2}$ \\ ${ }^{1}$ Department of Preventive Dentistry and Dental Public Health, School of Dentistry, Aichi Gakuin University, \\ 1-100 Kusumoto-cho, Chikusa-ku, Nagoya 464-8650, Japan \\ ${ }^{2}$ Project for Bio-index, Nutritional Epidemiology Program, The Incorporated Administrative Agency of Health \\ and Nutrition, 1-23-1 Toyama, Shinjuku-ku, Tokyo 162-8236, Japan
}

(Received May 7, 2008)

\begin{abstract}
Summary This study aimed to measure and evaluate the intakes for the four trace elements of $\mathrm{Fe}, \mathrm{Zn}, \mathrm{Mn}$, and $\mathrm{Cu}$ in 3- to 5-y-old Japanese preschool children. The study group consisted of a total of 90 3- to 5-y-old children living in Yokkaichi, Mie, Japan. Diet samples were collected by the duplicate-portion technique on $3 \mathrm{~d}$ at three different seasons between summer in 1999 and winter in 2000. The medians of annual mean daily intakes (25th75th percentile) of $\mathrm{Fe}, \mathrm{Zn}, \mathrm{Mn}$, and $\mathrm{Cu}$ in the 3 - to 5 -y-old children were $3.1 \mathrm{mg}$ (2.4 to 3.6), $4.0 \mathrm{mg}$ ( 3.4 to 4.7 ), $1.3 \mathrm{mg}$ (1.1 to 1.6 ), and $0.45 \mathrm{mg}$ (0.35 to 0.56 ), respectively. The annual mean value of the total daily diet intake had significant correlations with the $\mathrm{Fe}, \mathrm{Zn}$, $\mathrm{Mn}$ and $\mathrm{Cu}$ intakes (Spearman's $r=0.55,0.67,0.58$, and 0.55, respectively; $p<0.001$ for all). There were significant correlations between each mineral intake. The $\mathrm{Zn}$ and $\mathrm{Mn}$ intakes had differences among ages ( $p=0.003$ and 0.005 , respectively) and the Zn intake significantly differed between boys and girls $(p=0.031)$. The proportion of subjects whose $\mathrm{Mn}$ intake was the $\mathrm{AI}$ or less was $82 \%$, and the proportions of subjects whose $\mathrm{Fe}, \mathrm{Zn}$, and $\mathrm{Cu}$ intakes were the estimated average requirements (EARs) or less were 72,83 , and 13\%, respectively. Many Japanese children are deficient in Fe and Zn compared with the dietary reference intakes (DRIs). However, data in a balance study examining intakes and excretion of trace minerals are insufficient in children and DRIs for trace elements may change in future.
\end{abstract}

Key Words iron, zinc, manganese, copper, duplicate-diet technique

The essential elements whose daily dietary intakes in adults are below $100 \mathrm{mg}$ are called essential trace elements. Of these trace elements, four minerals of iron $(\mathrm{Fe})$, zinc $(\mathrm{Zn})$, manganese $(\mathrm{Mn})$ and copper $(\mathrm{Cu})$ have a daily intake of $1 \mathrm{mg}$ or more. Since central venous nutrition (CVN) was introduced, there have been many reports that patients receiving CVN become deficient in $\mathrm{Fe}, \mathrm{Zn}, \mathrm{Cu}$, and/or $\mathrm{Mn}$, and nutritional importance of these trace elements has attracted attention. The deficiencies of energy and protein are generally limited to certain areas where people suffer from poverty. However, it has gradually become apparent that people in affluent countries commonly have potential deficiencies of essential trace elements (1-4). Iron-deficiency anemia accounts for about $50 \%$ of anemia (5) and is not only the most interesting disease among trace element deficiencies, but also widely known. Castillo-Durán and Cassorla (6) reviewed trace mineral effects in human growth and development, and concluded that Fe deficiency may affect psychomotor development but did not appear to affect human growth, and that Zn deficiency may cause growth retardation. Zn deficiency is known to cause anorexia and hypogeusia etc. $(7,8)$. The study

E-mail: alice@dpc.agu.ac.jp using rats presented that long-term Zn deficiency decreased taste sensitivity in rats (9). In addition, it has been demonstrated that $\mathrm{Cu}, \mathrm{Mn}$ and $\mathrm{Zn}$ are essential in bone metabolism (10). However, the dietary reference intakes (DRIs) for such trace elements were established in 1999 in the 6th revision of the Recommended Dietary Allowances for the Japanese, which was used from April 2000 (11). The minerals whose recommended dietary allowances (RDAs) were established between 1947 and March 2000 were only three elements: sodium chloride $(\mathrm{NaCl})$, calcium $(\mathrm{Ca})$ and $\mathrm{Fe}$ $(11,12)$. $\mathrm{Zn}, \mathrm{Mn}$ and $\mathrm{Cu}$ were included in 11 minerals that were newly added in the 6th revision (from April 2000) (11), but evidence for the establishment of their RDAs does not contain much data on the mineral intakes and results in a balance study in children. The DRIs in children, therefore, have been often established by extrapolating those in adults and could greatly vary according to methods used for determining DRIs (11, 13). The RDA for Fe in 3- to 5-y-old children was $8 \mathrm{mg}$ in boys and girls for half a century until 2005 but decreased by $38 \%$ to $5 \mathrm{mg}$ in the Dietary Reference Intakes 2005. Although the National Health and Nutrition Survey (NHNS) was called the National Nutrition Survey (NNS) until 2001, in this paper all these surveys 
are referred to as NHNS. The NHNSs indicated that Fe intakes in 2001 or later decreased by $30 \%$ or more compared with those until 2000. Such changes are thought to result from revisions of the Japanese Standard Tables of Food Composition (hereinafter "food composition table").

In order to assess daily intakes for trace elements without depending on the food composition table, in view of cooking effects and seasonal variation, we determined $\mathrm{Fe}, \mathrm{Zn}, \mathrm{Mn}$, and $\mathrm{Cu}$ intakes in Japanese children aged 3 to $5 \mathrm{y}$ using the duplicate-diet technique.

\section{SUBJECTS AND METHODS}

Subjects and sample collection. A total of 94 children ( 30 children aged 3 y, 30 children aged 4 y, and 34 children aged 5 y) from nursery schools and kindergartens in Yokkaichi, Mie, Japan, participated in the survey. Duplicate portions of all foods and drinks that they consumed were collected by the duplication-portion technique for a total of $3 \mathrm{~d}$ on $1 \mathrm{~d}$ each in summer, autumn and winter during the year 1999 school (April 1999 to March 2000) (14). Duplicate diets were collected on normal days, not special days for events in nursery schools or kindergartens and at home, so that regular meals could be collected as samples. The total number of days of diet sample collection was 19 (7 d in summer, $6 \mathrm{~d}$ in autumn, and $6 \mathrm{~d}$ in winter) in all 94 children. We explained in advance the survey method to all parents of the subjects and staff in the nursery schools and kindergartens. The parents who could not participate in the explanation meeting individually received an explanation of the duplication-portion technique. All parents and staff in the nursery schools and kindergartens were asked to maintain a regular meal pattern, to remove uneaten food such as fishbone and fruit peel from the meal samples and to record the menu, names of materials, and weight of the portion eaten.

Diet samples were collected at home by the parents as follows: a duplicate portion of foods and drinks that a subject consumed at home and tea in a water bottle that a subject brought from home and consumed in the nursery school or kindergarten was put into a previously-provided polyethylene jar with a polypropylene cap (\#2104-0032, NALGEN, USA) and stored in a refrigerator, and the collected sample was brought to the nursery school or kindergarten, or handed to the staff in a kindergarten bus on the following morning. In the kindergarten or nursery school, diet samples were similarly collected for all foods and drinks other than tea in a water bottle brought from home, with help from teachers of the subjects. All diet samples collected by the duplicate-portion technique were then stored in the plastic jars. The plastic jars were put in cool containers $\left(4^{\circ} \mathrm{C}\right)$ and carried to the laboratory immediately after sample collection. The total diet consumed was weighed using a balance (AG245, METTLER TOLEDO, Switzerland) and the daily intake was recorded. The contents of diets collected were confirmed from dietary records to be regular meals. The diet samples were homogenized using a commercial blender (HGB-SS, Warring, USA) with a given amount of distilled water at 19,000 rpm for $10 \mathrm{~min}$. After homogenization, the samples were vacuum packed by an automated vacuum packaging machine (Tospack V222, Tosei, Japan) and stored at $-30^{\circ} \mathrm{C}$. The frozen samples from 4 boys aged $5 \mathrm{y}$ were randomly excluded from those from 94 preschool children, and the samples from 90 children including 30 children (15 boys and 15 girls) each in the 3-, 4, and 5y-old children groups were subjected to this study. The body weight (mean \pm SD) was $15.1 \pm 2.2 \mathrm{~kg}$ in 3 -y-old children, $17.0 \pm 1.3 \mathrm{~kg}$ in 4 -y-old children, and $19.1 \pm 2.7 \mathrm{~kg}$ in 5 -y-old children. We present in Table 1 the physical constitution of the subjects participating in this study according to age and sex.

The protocol of this study was reviewed and approved by the Ethical Committee of Aichi-Gakuin University.

Reagents and analysis. The 270 frozen diet samples collected on 19 different days ( $3 \mathrm{~d}$ for each child) were thawed. A diet sample was divided into three samples for analysis (a total of 810 samples). About 15 to $20 \mathrm{~g}$ of the sample was transferred into a 100-mL beaker (Pyrex, Iwaki Glass, Japan). Concentrated nitric acid (UGR grade, Kanto Chemical Co., Inc., Japan), 5 mL, was added to the sample and the beaker was covered with plastic wrap for contamination prevention and allowed to stand on a hot plate (HTP552AA, ADVANTEC, Japan) at $90^{\circ} \mathrm{C}$ for $24 \mathrm{~h}$. The dried sample was removed from the hot plate and $1 \mathrm{~mL}$ of hydrogen peroxide solution (Wako Pure Chemical Industries, Ltd., Japan) was added to the sample. The sample was allowed to stand on the hot plate at $120^{\circ} \mathrm{C}$ for about $3 \mathrm{~min}$ and then $5 \mathrm{~mL}$ of concentrated nitric acid was added. The sample was allowed to stand at $120^{\circ} \mathrm{C}$ for $48 \mathrm{~h}$. Hydrogen peroxide solution, $0.25 \mathrm{~mL}$, and $1 \mathrm{~mL}$ of concentrated nitric acid were added to the sample until the solution became clear and the sample was wet ashed for about $1 \mathrm{wk}$ (15-17). After wet ashing, the beaker was ultrasonic-washed with $0.5 \mathrm{M}$ nitric acid for collecting minerals attached to the beaker. Nitric acid $(0.5 \mathrm{M})$ was added to the sample to make $50 \mathrm{~mL}$ and the sample was stored.

The sample was diluted to concentrations where trace elements (Fe, $\mathrm{Zn}, \mathrm{Mn}$ and $\mathrm{Cu}$ ) were measurable by atomic absorption spectrometry to determine the four minerals in the sample with an atomic absorption spectrometer (Z-8200, HITACHI, Japan) using acetylene gas for atomic absorption spectrometry.

The samples were analyzed with a known sample, the ARC/CL total diet reference materials (HDP) of the Agricultural Research Center of Finland, Institute of Food Research and Central Laboratory, to determine the recoveries.

On the other hand, data obtained by the dietary record method was also analyzed using nutrient calculation software based on the 5 th revised edition of the Standard Tables of Food Composition in Japan (18) (Bssic-4 for Windows Version 2.1, Kagawa Nutrition University Publishing Division).

Statistical analysis. The statistical analysis was performed using SPSS 11.0J with a significance probability 
Table 1. Body weights, body heights and Kaup indexes in 3- to 5-y-old Japanese children.

\begin{tabular}{|c|c|c|c|c|}
\hline \multirow{2}{*}{$\begin{array}{l}\text { Age }^{1} \\
\text { Sex }\end{array}$} & \multicolumn{4}{|c|}{ This survey in 1999-2000 } \\
\hline & $\begin{array}{c}\text { Subjects } \\
n\end{array}$ & $\begin{array}{l}\text { Body weight }(\mathrm{kg}) \\
\text { Mean } \pm \text { SD }\end{array}$ & $\begin{array}{l}\text { Body height }(\mathrm{cm}) \\
\text { Mean } \pm \text { SD }\end{array}$ & $\begin{array}{l}\text { Kaup index } \\
\text { Mean } \pm \text { SD }\end{array}$ \\
\hline $3 \mathrm{y}$ & 30 & $15.1 \pm 2.2$ & $99.3 \pm 4.4$ & $15.2 \pm 1.4$ \\
\hline Boys & 15 & $14.8 \pm 1.5$ & $98.8 \pm 4.5$ & $15.1 \pm 1.1$ \\
\hline Girls & 15 & $15.4 \pm 2.8$ & $99.8 \pm 4.4$ & $15.3 \pm 1.7$ \\
\hline $4 \mathrm{y}$ & 30 & $17.0 \pm 1.3$ & $105.5 \pm 3.1$ & $15.3 \pm 1.0$ \\
\hline Boys & 15 & $17.0 \pm 1.0$ & $105.3 \pm 3.6$ & $15.4 \pm 0.9$ \\
\hline Girls & 15 & $17.0 \pm 1.6$ & $105.6 \pm 2.6$ & $15.2 \pm 1.1$ \\
\hline $5 \mathrm{y}$ & 30 & $19.1 \pm 2.7$ & $112.3 \pm 5.0$ & $15.1 \pm 1.6$ \\
\hline Boys & 15 & $19.1 \pm 3.3$ & $111.1 \pm 5.3$ & $15.4 \pm 1.7$ \\
\hline Girls & 15 & $19.2 \pm 2.1$ & $113.4 \pm 4.7$ & $14.9 \pm 1.4$ \\
\hline
\end{tabular}

\footnotetext{
${ }^{1}$ As of the beginning of the preschool year (April 2, 1999).
}

of $p<0.05$. Normality was evaluated by the ShapiroWilk test. Since with the exception of $\mathrm{Zn}$ the daily dietary intakes of $\mathrm{Fe}, \mathrm{Mn}$ and $\mathrm{Cu}$ in 3- to 5-y-old children were not normally distributed, data on four minerals were expressed as medians and 25th-75th percentiles. For comparison with data in other surveys, data was also presented as means, standard deviations (SDs) and ranges.

For the $\mathrm{Fe}, \mathrm{Zn}, \mathrm{Mn}$, and $\mathrm{Cu}$ intakes, the Kruskal-Wallis and the Mann-Whitney test were used to compare differences among ages and between boys and girls, respectively. Correlations between each mineral intake were evaluated using Spearman rank-correlation coefficients.

Evaluation of daily intakes. The daily intakes of four trace elements by the duplicate-portion technique and the daily energy intakes by the dietary record method in this survey were compared with data in the NHNS 2003 (performed in November) (19). Since there were seasonal variations in the trace mineral intakes by the duplicate-portion technique in this survey, the data in autumn was used in the above comparison. The daily intakes of $\mathrm{Fe}, \mathrm{Zn}, \mathrm{Mn}$, and $\mathrm{Cu}$ by the duplicate-portion technique were also expressed as percentiles and compared with the DRIs in 2005 (13).

\section{RESULTS}

The recoveries (coefficient of variations) of Fe, $\mathrm{Zn}, \mathrm{Mn}$ and $\mathrm{Cu}$ that were determined using a known sample, the ARC/CL total diet reference material (HDP) of the Agricultural Research Centre of Finland, Institute of Food Research and Central Laboratory, were 92.2\% (6.4), 94.3\% (4.8), 96.2\% (5.7) and 91.8\% (5.3), respectively.

The body weights (mean \pm SD) of children aged 3, 4, and $5 \mathrm{y}$ in this study were $14.8 \pm 1.5 \mathrm{~kg}$ for boys and $15.4 \pm 2.8 \mathrm{~kg}$ for girls; $17.1 \pm 1.0 \mathrm{~kg}$ for boys and $17.0 \pm 1.6 \mathrm{~kg}$ for girls; and $19.1 \pm 3.3 \mathrm{~kg}$ for boys and $19.2 \pm 2.1 \mathrm{~kg}$ for girls, respectively, and the mean Kaup index was approximately 15 for both boys and girls in all age groups (Table 1 ). The total daily diet intakes (mean \pm SD) in 3-, 4- and 5-y-old children were 1,194士
Table 2. Daily intakes of total diet in 3- to 5-y-old Japanese children $(n=90)$.

\begin{tabular}{|c|c|c|c|c|}
\hline \multirow{2}{*}{ Group } & $\mathrm{g} / \mathrm{d}$ & \multirow{2}{*}{$p$ value $^{1}$} & $\mathrm{~g} / \mathrm{d} / \mathrm{BW}$ & \multirow{2}{*}{$p$ value } \\
\hline & Mean \pm SD & & Mean \pm SD & \\
\hline $3 y$ & $1,194 \pm 231$ & $0.008^{* *}$ & $80 \pm 16$ & 0.324 \\
\hline $4 y$ & $1,322 \pm 211$ & & $78 \pm 13$ & \\
\hline $5 y$ & $1,340 \pm 253$ & & $74 \pm 13$ & \\
\hline 3-5 Boys & $1,333 \pm 221$ & 0.254 & $79 \pm 13$ & 0.107 \\
\hline 3-5 Girls & $1,277 \pm 267$ & & $75 \pm 15$ & \\
\hline All & $1,305 \pm 245$ & & $77 \pm 14$ & \\
\hline
\end{tabular}

${ }^{1}$ Differences among the age groups were determined with the Kruskal-Wallis test, and differences between boys and girls were determined with the Mann-Whitney $U$ test. ${ }^{* *} p<0.01$.

$231,1,322 \pm 211$, and $1,340 \pm 151 \mathrm{~g}$, respectively, showing a significant difference among age groups $(p=0.008)$ (Table 2).

Table 3 shows the annual mean values of the daily dietary intakes and the daily dietary intakes per weight of $\mathrm{Fe}, \mathrm{Zn}, \mathrm{Mn}$ and $\mathrm{Cu}$ in 3- to 5-y-old children. The daily $\mathrm{Zn}$ and $\mathrm{Mn}$ intakes showed significant differences among ages ( $p=0.003$ and $p=0.005$, respectively), and the daily $\mathrm{Zn}$ intake also had a significant difference between boys and girls $(p=0.031)$. In addition, the daily $\mathrm{Zn}$ intake per body weight significantly differed between boys and girls $(p=0.004)$. The medians of annual mean daily intakes (25th-75th percentile) of Fe, $\mathrm{Zn}, \mathrm{Mn}$ and $\mathrm{Cu}$ were $3.1 \mathrm{mg}$ (2.4 to 3.6), $4.0 \mathrm{mg}$ (3.4 to 4.7 ), $1.3 \mathrm{mg}$ (1.1 to 1.6 ), and $0.45 \mathrm{mg}$ (0.35 to 0.56$)$, respectively.

Table 4 presents correlations between the total daily diet intake and each mineral intake. The annual mean value of total daily diet intake had significant correlations with $\mathrm{Fe}, \mathrm{Zn}, \mathrm{Mn}$ and $\mathrm{Cu}$ intakes (Spearman's $r=0.55,0.67,0.58$, and 0.55 , respectively; $p=0.001$ 


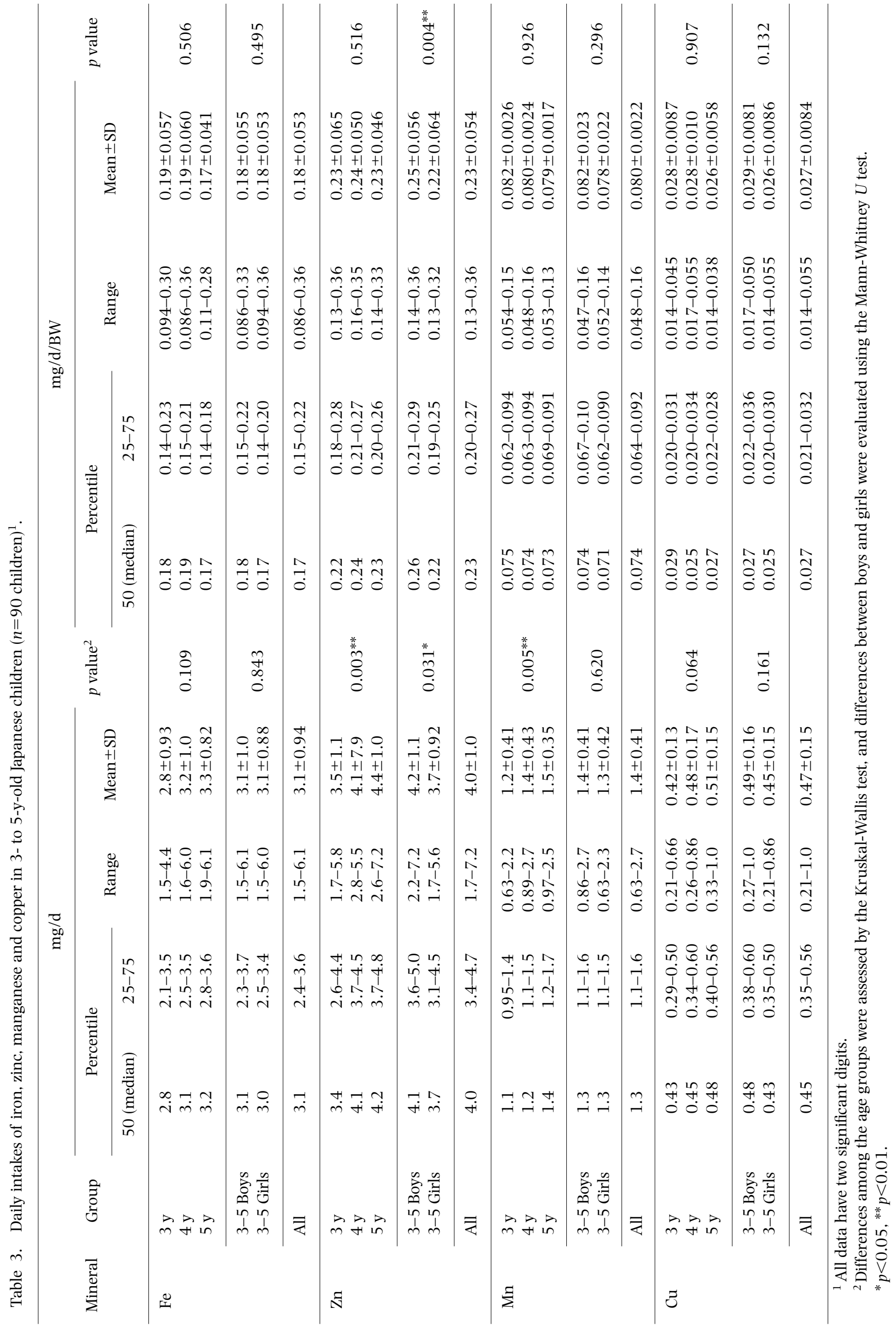


for all). As for correlations between each mineral (annual mean daily intake), there were significant correlations between each mineral $(p=0.000)$.

Table 5 compares the daily intakes in 3- to 5-y-old children in autumn with data in the NHNS 2003 (19). The daily energy intake in this study (99\%) was similar to that in the NHNS 2003, but the daily intakes of Fe, $\mathrm{Zn}$, and $\mathrm{Cu}$ in this study were lower with 58, 67, and $63 \%$, respectively, as compared with those in the NHNS 2003.

Table 6 lists the percentiles of daily intakes and the DRIs 2005 (13) for Fe, Zn Mn and Cu in Japanese children aged 3 to $5 \mathrm{y}$. For $\mathrm{Fe}, \mathrm{Zn}$, and $\mathrm{Cu}$, the proportions of subjects whose intake levels were not more than the estimated average requirements (EARs) were 72, 83, and $13 \%$, respectively. As for $\mathrm{Mn}$, the median intake in the study population was $1.3 \mathrm{mg}$ and was less than its adequate intake (AI) of $1.7 \mathrm{mg}$.

\section{DISCUSSION}

We considered that dietary intakes of children in this study were typical data for children in Japan and could be compared with data in the NHNS 2003 in view of the following: (1) the number of days of diet sample col- lection by the duplicate-portion technique was 3 for a year for each subject and the total number of days of diet sample collection was 19 in all subjects $(7 \mathrm{~d}$ in summer, $6 \mathrm{~d}$ in autumn and $6 \mathrm{~d}$ in winter); (2) we planned to collect diet samples on normal days, not special days for events, and confirmed that the collected samples were routine meals by checking them against the dietary records after sample collection; (3) the body weights of the subjects in this study were approximately equal to those of children in the NHNS; and (4) the dietary energy intake (mean \pm SD) by the dietary record

Table 4. Spearman's correlation coefficient between each nutrient ( $n=90$ children).

\begin{tabular}{lccccc}
\hline & Total diet & $\mathrm{Fe}$ & $\mathrm{Zn}$ & $\mathrm{Mn}$ & $\mathrm{Cu}$ \\
\hline Total diet & - & $* * *$ & $* * *$ & $* * *$ & $* * *$ \\
$\mathrm{Fe}$ & 0.55 & - & $* * *$ & $* * *$ & $* * *$ \\
$\mathrm{Zn}$ & 0.67 & 0.69 & - & $* * *$ & $* * *$ \\
$\mathrm{Mn}$ & 0.58 & 0.55 & 0.63 & - & $* * *$ \\
$\mathrm{Cu}$ & 0.55 & 0.58 & 0.64 & 0.62 & - \\
\hline \multicolumn{2}{l}{${ }^{* * *} p<0.001}$.
\end{tabular}

Table 5. Comparison of the daily intake of iron, zinc, manganese and copper in 3- to 5-y-old Japanese children using the duplicate-portion technique versus the National Nutrition Survey (Mean values and standard deviations).

\begin{tabular}{|c|c|c|c|c|c|c|c|}
\hline \multirow{3}{*}{ Mineral } & \multicolumn{7}{|c|}{ Mean \pm SD } \\
\hline & \multicolumn{3}{|c|}{$\begin{array}{l}\text { Daily intake in autumn by the } \\
\text { duplicate-portion technique }^{1}(n)\end{array}$} & \multicolumn{3}{|c|}{$\begin{array}{l}\text { Daily intake by the National Nutrition } \\
\text { Survey in } 2003 \text { (Ministry of Health, } \\
\text { Labour and Welfare, Japan 2005) (n) }\end{array}$} & \multirow{2}{*}{$\begin{array}{c}\text { As a percentage of } \\
\text { the National } \\
\text { Nutrition Survey }\end{array}$} \\
\hline & All (90) & Boys (45) & Girls (45) & All (305) & Boys (162) & Girls (143) & \\
\hline $\mathrm{Fe} \mathrm{mg} / \mathrm{d}$ & $2.9 \pm 1.3$ & $3.0 \pm 1.5$ & $2.8 \pm 1.1$ & $5.0 \pm 2.6$ & $5.1 \pm 3.3$ & $5.0 \pm 1.7$ & $58 \%$ \\
\hline $\mathrm{Zn} \mathrm{mg/d}$ & $3.8 \pm 1.2$ & $4.0 \pm 1.3$ & $3.5 \pm 1.0$ & $5.7 \pm 1.7$ & $5.8 \pm 1.9$ & $5.6 \pm 1.3$ & $67 \%$ \\
\hline $\mathrm{Mn} \mathrm{mg} / \mathrm{d}$ & $1.4 \pm 0.60$ & $1.5 \pm 0.58$ & $1.4 \pm 0.63$ & - & - & - & - \\
\hline $\mathrm{Cu} \mathrm{mg} / \mathrm{d}$ & $0.47 \pm 0.21$ & $0.49 \pm 0.24$ & $0.46 \pm 0.17$ & $0.75 \pm 0.25$ & $0.74 \pm 0.26$ & $0.75 \pm 0.23$ & $63 \%$ \\
\hline $\begin{array}{l}\text { Energy }^{2} \\
\mathrm{kcal} / \mathrm{d}\end{array}$ & $1,330 \pm 326$ & $1,357 \pm 320$ & $1,302 \pm 334$ & $1,349 \pm 322$ & $1,359 \pm 350$ & $1,337 \pm 287$ & $99 \%$ \\
\hline
\end{tabular}

${ }^{1}$ As significant seasonal differences were noticed in the data for each daily intake, we utilized only the autumn data as the National Nutrition Survey collected its entire data in $1 \mathrm{~d}$ in the autumn.

${ }^{2}$ The energy intakes were determined by the dietary record method.

Table 6. Distribution (percentiles) of daily intakes of iron, zinc, manganese and copper by 3- to 5-y-old Japanese children and evaluation based on the Dietary Reference Intakes (DRIs).

\begin{tabular}{|c|c|c|c|c|c|c|c|c|c|c|c|c|c|c|}
\hline & \multicolumn{14}{|c|}{ Percentiles } \\
\hline & 1 & 5 & 10 & & 25 & & 50 & & 75 & & 90 & 95 & & 99 \\
\hline $\mathrm{Fe}(\mathrm{mg})$ & 1.5 & 1.7 & 1.9 & & 2.4 & & 3.1 & $\Delta$ & 3.6 & & 4.2 & 4.4 & $\triangle$ & 6.0 \\
\hline $\mathrm{Zn}$ (mg) & 2.0 & 2.3 & 2.6 & & 3.4 & & 4.0 & & 4.7 & $\Delta$ & 5.4 & 5.5 & $\triangle$ & 6.5 \\
\hline $\mathrm{Mn}(\mathrm{mg})$ & 0.74 & 0.88 & 0.9 & & 1.1 & & 1.3 & & 1.6 & $\uparrow$ & 2.0 & 2.2 & & 2.49 \\
\hline $\mathrm{Cu}(\mathrm{mg})$ & 0.22 & 0.27 & 0.28 & $\Delta$ & 0.35 & $\triangle$ & 0.45 & & 0.56 & & 0.64 & 0.75 & & 0.88 \\
\hline
\end{tabular}

EAR $(\Delta)$ Fe: $3.5 \mathrm{mg} / \mathrm{d}$, Zn: $5 \mathrm{mg} / \mathrm{d}$, Cu: $0.3 \mathrm{mg} / \mathrm{d}$. RDA $(\triangle)$ Fe: $5.0 \mathrm{mg} / \mathrm{d}, \mathrm{Zn}: 6 \mathrm{mg} / \mathrm{d}$, Cu: boys 0.4; girls $0.3 \mathrm{mg} / \mathrm{d}$. AI ( $\uparrow)$ Mn: 1.7 mg/d. UR Fe: 25 mg/d. 
method was $1,330 \pm 326 \mathrm{kcal}$ in this study and $1,349 \pm 322 \mathrm{kcal}$ in the NHNS 2003, showing no significant difference in the dietary energy intake (Table $5)$.

The duplicate-diet technique reflects actual nutrient intakes by directly analyzing samples without depending on the subject's memory or accuracy of the food composition table and would be a reliable method in the survey for dietary intakes. This technique has high accuracy, but puts a great burden on subjects and costs time and money for the sample analysis. Therefore, there have been not many reports on studies using the duplicate-portion technique. On the other hand, the dietary record method and the 24-h recall method have been widely used in the nutrition survey, but their assumption of nutrient intakes depends on the food composition table. Since the food composition table is generally prepared based on the analytical values of raw foods, the nutrient intakes estimated from cooked food would not be accurate. Kimura and Itokawa (20) have reported that the cooking losses of minerals are large and 30 to $40 \%$ of minerals are lost during cooking. The cooking loss of $\mathrm{Zn}$ is above $80 \%$ (20). Okada et al. (21) reported that in the study where cooked hospital foods collected for $42 \mathrm{~d}$ were analyzed, the Fe intake analyzed was $62 \%$ of the value calculated from the food composition table and the cooking loss of Fe was large. These results indicate that the mineral intake estimated from the food composition table was accurate in calculation but was higher than the actual intake level. In the comparison of the calculated values from the food composition table with the analytical values of food materials before cooking, they reported that the $\mathrm{Zn}, \mathrm{Cu}$ and $\mathrm{Mn}$ intakes had no significant differences but the analytical value for Fe was significant lower with $75 \%$ of the calculated value. In addition, Skibniewska (22) indicated effects of mineral losses due to use of processed food.

The daily intakes for $\mathrm{Fe}, \mathrm{Zn}$, and $\mathrm{Cu}$ in 3- to 5-y-old children in this study were about 60 to $70 \%$ of those in the NHNS 2003 (19) using the 5th revision (18) of the food composition table modified for the Fe value; the Fe intake level was especially low (Table 5). Considering the recoveries in the known sample were 92 to $96 \%$, differences in the mineral intakes between our study and the National Nutrition Survey do not result from analytical precision. Although, as stated above, the analytical values for minerals were lower than the calculated values, especially for $\mathrm{Fe}$, despite the use of the 5th revision (18) of the food composition table, such results were also similarly observed in the studies using the 4th (23) revision by Kimura and Itokawa (20) and Okada et al. (21). In the comparison of mineral intakes by the dietary record method with those by the duplicate-portion technique in German children aged 5 to $9 \mathrm{y}$, the median calculated and analyzed intakes were 5.3 and $5.6 \mathrm{mg}$ for $\mathrm{Zn}$ and 0.6 and $1.1 \mathrm{mg}$ for $\mathrm{Cu}$, respectively; the analyzed values by the duplicate-portion technique were lower than the calculated values by the dietary record method (3). Although such differ- ences might result from differences between the food composition values used in the preparation of the food composition table and those in this survey, we think that the differences could be greatly attributed to mineral loss due to cooking. As Horst et al. (24) indicated that a difference in weights between the 24-h recall method and the duplicate-portion technique is one of the factors of the systematic difference between both methods, the differences in the mineral intakes between our study and the NHNS were thought to result from errors in the calculated values.

In the study by Laryea et al. (3) in German children aged 5 to $9 \mathrm{y}$, the median $\mathrm{Zn}$ and $\mathrm{Cu}$ intakes were 5.3 and $0.6 \mathrm{mg}$, respectively. We searched reports on Fe, Zn, $\mathrm{Mn}$ and $\mathrm{Cu}$ intakes in Japanese children by the duplicate-portion technique using PubMed. The PubMed search using the keywords of trace, element, duplicate, and Japanese with the age range of 2 to $5 \mathrm{y}$, produced only one article by Aung et al. (25), which reported that the mean $\mathrm{Zn}, \mathrm{Mn}$, and $\mathrm{Cu}$ intakes in 3- to 6-y-old children living in central Tokyo were 4,930, 1,560 and $567 \mu \mathrm{g}$, respectively. We also compared our study results with reports published in Japanese journals. The review on trace mineral intakes in Japanese children by Suzuki and Goto (26) reported that the respective mean intakes of $\mathrm{Fe}, \mathrm{Zn}$, and $\mathrm{Cu}$ were 11.68, 12.0, and $3.23 \mathrm{mg}$ in 5.3- to 9.8-y-old children (27) and 9.0, 7.7, and $1.2 \mathrm{mg}$ in 3.4 - to 6.8 -y-old children (28). The mineral intakes reported in old Japanese articles are obviously higher, as compared with the mean values in this study (Fe $3.1 \mathrm{mg}$, Zn $4.0 \mathrm{mg}$, Mn $1.4 \mathrm{mg}$, and $\mathrm{Cu}$ $0.47 \mathrm{mg}$ ) as well as those reported by Laryea et al. (3) and by Aung et al. (25). The reason why the previous Japanese data apparently tend to show higher intake levels is that the data may have some effects of measuring methods, materials, apparatus, etc., used in the study.

Table 6 lists the percentiles of daily intakes and the DRIs 2005 (13) for Fe, Zn Mn and Cu in Japanese children aged 3 to $5 \mathrm{y}$. The EARs for $\mathrm{Fe}, \mathrm{Zn}$ and $\mathrm{Cu}$ are 3.5, 5.0 , and $0.3 \mathrm{mg}$, respectively, and the proportions of subjects whose intake levels were not more than the EARs were 72,83 , and $13 \%$, respectively. If the proportion of the subjects with not more than EAR in the study population approximately corresponds to that of children with an insufficient mineral intake, there would be considerable numbers of the subjects deficient in $\mathrm{Fe}, \mathrm{Zn}$, and $\mathrm{Cu}$. As for $\mathrm{Mn}$, since the median intake in the study population was $1.3 \mathrm{mg}$ and was less than its AI of $1.7 \mathrm{mg}$, we can not easily determine how many subjects had insufficient Mn intake. Comparison of the recommended nutritional requirements in 3- to 5-y-old children in the Dietary Reference Intakes for Japanese 2005 (13) with those in the 6th revision of the Recommended Dietary Allowances for Japanese 1999 (11) shows that the $\mathrm{Fe}, \mathrm{Mn}$, and $\mathrm{Cu}$ intakes decreased by 40 to $60 \%$, from 8.0 to $5.0 \mathrm{mg}, 2.5$ to $1.7 \mathrm{mg}$, and 1.0 to $0.4 \mathrm{mg}$, respectively. However, it has not been long since the DRIs for trace elements were established and there is insufficient data in a balance study examining the 
intake and excretion of trace elements, especially in children. It, therefore, is necessary to solve problems on differences in absorption and bioavailability of trace elements, and interactions of trace elements with other elements, etc. Considering these situations, when trace element intakes are further studied and data on trace elements is increased, the DRIs for trace elements may change in the future.

We examined changes in nutrient intakes in the NHNSs from 1975 to 2004, and the Fe intake remarkably decreased in 2001 or later as compared with other nutrient intakes. The 4th revision of the Japanese standard tables of food composition (23) had been used in nutrient surveys until the NHNS 2000 (29), but from 2001 the 5 th revision $(18)$ has been used. The 5 th revision includes various modifications in mineral items, imported food items, and cooked food items and it is obvious that the nutrient intakes in the NHNSs in 2001 or later reflect changes in the food composition table.

The present study showed differences in the $\mathrm{Zn}$ and $\mathrm{Mn}$ intakes among ages and a difference in the $\mathrm{Zn}$ intake between boys and girls (Table 3). The survey for daily mineral intakes by a model menu method in Japanese adults by Ikebe et al. (30) reported that the Mn and $\mathrm{Zn}$ intakes were significantly higher in men than women and they indicated that this difference would depend on a difference in the total diet intake between men and women. The intakes of four trace elements in the children were strongly correlated with the total diet intake; in particular, there was a high correlation between the $\mathrm{Zn}$ intake and the total diet intake (Table 4). In children, the body weight and the total diet intake significantly differed among ages, but there were no obvious sexual differences in those that were observed in adults (Tables 1 and 2). We speculate that such differences influence differences in trace element intakes of children among ages and between boys and girls.

The samples in this study were collected from 1999 to 2000 and we will soon analyze the samples to examine the effects of the trend of the times on the mineral intakes.

\section{Acknowledgments}

We would like to thank all participants, their parents and the staff of the preschools for their support. This study was partly funded by the Ministry of Health, Labour and Welfare Scientific Research Grant (H15Iryo-Ippan-020) and supported partly by a grant from the AGU High-tech Research Centre Project for Private Universities.

None of the authors had a conflict of interest.

\section{REFERENCES}

1) Abdulla M. 1983. Public health/clinical significance of inorganic chemical elements. Experientia Suppl 44: 339-355.

2) Abdulla M, Behbehani A, Dashti H. 1989. Dietary intake and bioavailability of trace elements. Biol Trac Elem Res 21: 173-178.

3) Laryea MD, Schnittert B, Kersting M, Wilhelm M,
Lombeck I. 1995. Macronutrient, copper, and zinc intakes of young German children as determined by duplicate food samples and diet records. Ann Nutr Metab 39: 271-278.

4) Lombardi-Boccia G, Aguzzi A, Cappelloni M, Di Lullo G, Lucarini M. 2003. Total-diet study: dietary intakes of macro elements and trace elements in Italy. $\mathrm{Br} J \mathrm{Nutr}$ 90: $1117-1121$.

5) Merson MH, Black RE, Mills AJ. 2001. International Public Health: Disease, Programs, Systems, and Policies, p 238. AN Aspen Publication, Githersburg.

6) Castillo-Durán C, Cassorla F. 1999. Trace minerals in human growth and development. J Pediatr Endocrinol Metab 12: 589-601.

7) Hambidge KM, Hambidge C, Jacobs M, Baum JD. 1972. Low levels of zinc in hair, anorexia, poor growth, and hypogeusia in children. Pediatr Res 6: 868-874.

8) Arakawa T, Tamura T, Igarashi Y, Suzuki H, Sandstead HH. 1976. Zinc deficiency in two infants during total parenteral alimentation for diarrhea. Am J Clin Nutr 29: 197-204.

9) Goto T, Komai M, Suzuki H, Furukawa Y. 2001. Longterm zinc deficiency decreases taste sensitivity in rats. $J$ Nutr 131: 305-310.

10) Saltman PD, Strause LG. 1993. The role of trace minerals in osteoporosis. J Am Coll Nutr 12: 384-389.

11) Ministry of Health and Welfare, Japan. 1999. Recommended Dietary Allowances for the Japanese 6th Revision (1999), p 199-273. Dai-ichi Shuppan Publishing, Tokyo (in Japanese).

12) Ministry of Health and Welfare, Japan. 1996. Recommended Dietary Allowances for the Japanese 5th Revision (1994). Dai-ichi Shuppan Publishing, Tokyo (in English and Japanese).

13) Ministry of Health, Labour, and Welfare, Japan. 2005. Dietary Reference Intakes for Japanese, 2005. Dai-ichi Shuppan Publishing, Tokyo (in Japanese).

14) Murakami T, Narita N, Nakagaki H, Shibata T, Robinson C. 2002. Fluoride intake in Japanese children aged 35 years by the duplicate-diet technique. Caries Res $\mathbf{3 6}$ : 386-390.

15) Nishimuta M, Kodama N, Morikuni E, Yoshioka YH, Yamada H, Kitajima H, Takeyama H, Suzuki K. 2004. Balances of calcium, magnesium and phosphorus in Japanese young adults. J Nutr Sci Vitaminol 50: 19-25.

16) Kodama N, Morikuni E, Matsuzaki N, Yoshioka YH, Takeyama H, Yamada H, Kitajima H, Nishimuta M. 2005. Sodium and potassium balances in Japanese young adults. J Nutr Sci Vitaminol 51: 161-168.

17) Nishimuta M, Kodama N, Morikuni E, Yoshioka YH, Matsuzaki N, Takeyama H, Yamada H, Kitajima H. 2005. Positive correlation between dietary intake of sodium and balances of calcium and magnesium in young Japanese adults-low sodium intake is a risk factor for loss of calcium and magnesium. J Nutr Sci Vitaminol 51: 265-270.

18) Science and Technology Agency, Japan. 2000. Standard Tables of Food Composition in Japan, 5th Revised Ed. Ookurashou Insatukyoku, Tokyo (in Japanese).

19) Ministry of Health, Labour, and Welfare, Japan. 2005. The National Health and Nutrition Survey in Japan, 2003. Dai-ichi Shuppan Publishing, Tokyo (in Japanese).

20) Kimura M, Itokawa Y. 1990. Cooking losses of minerals in foods and its nutritional significance. J Nutr Sci Vita- 
minol 36 (Suppl 1): S25-32.

21) Okada K, Matsumura A, Manabe S, Sakamoto S, Ohnaka M, Nakaya Y. 1997. Loss of dietary minerals following cooking in therapeutic diets for nephropathy-Comparison of calculated values by the Food Table to measured values- - Nippon Eiyo Shokuryo Gakkaishi (J Jpn Soc Nutr Food Sci) 50: 349-354 (in Japanese).

22) Skibniewska KA. 2002. Estimation of iron, copper, zinc and manganese intake from duplicate diets provided by hospitals in Poland, 1993-96. Addit Conta Food 19: 969-973.

23) Science and Technology Agency, Japan. 1982. Standard Tables of Food Composition in Japan, 4th Revised Ed. Ookurashou Insatukyoku, Tokyo (in Japanese).

24) Horst CH, Obermann-De Boer GL, Kromhout D. 1988. Validity of the 24-hour recall method in infancy: the Leiden Pre-School children study. Int J Epidemiol 17: 217-221.

25) Aung NN, Yoshinaga J, Takahashi JI. 2006. Dietary intake of toxic and essential trace elements by the children and parents living in Tokyo Metropolitan Area,
Japan. Food Addit Contam 23: 883-894.

26) Suzuki K, Goto S. 1987. Trace minerals intake and its balance in Japanese young children. Nippon Eiyo Shokuryo Gakkaishi (J Jpn Soc Nutr Food Sci) 40: 443450 (in Japanese).

27) Suzuki K, Hayakawa T, Hasegawa Y. 1956. Copper, manganese, zink and iron balances in Japanese children. Kokuritsu Eiyo Kenkyusho Kenkyu Hokoku (Annual Report of the National Institute of Nutrition) 5: 39-42 (in Japanese).

28) Suzuki K. 1987. The mineral balance of young Japanese children. Nippon Ika Daigaku Igakukai Zasshi (J Nippon Med Sch) 54: 485-508 (in Japanese).

29) Ministry of Health, Labour, and Welfare, Japan. 2000. The National Nutrition Survey in 2000. Dai-ichi Shuppan Publishing, Tokyo (in Japanese).

30) Ikebe K, Nisimune T, Tanaka R. 1990. Dairy intakes of 15 metals according to the model menu. Shokuhin Eiseigaku Zasshi (J Food Hygienic Soc of Jpn) 31: 280-284 (in Japanese). 